The University of Maine

DigitalCommons@UMaine

Marine Sciences Faculty Scholarship

School of Marine Sciences

$1-21-2004$

\title{
Particulate Backscattering Ratio at Leo 15 and Its Use to Study Particle Composition and Distribution
}

Emmanuel Boss

University of Maine - Main, emmanuel.boss@maine.edu

W. S. Pegau

M. Lee

M. Twardowski

E. Shybanov

See next page for additional authors

Follow this and additional works at: https://digitalcommons.library.umaine.edu/sms_facpub

\section{Repository Citation}

Boss, Emmanuel; Pegau, W. S.; Lee, M.; Twardowski, M.; Shybanov, E.; Korotaev, G.; and Baratange, F., "Particulate Backscattering Ratio at Leo 15 and Its Use to Study Particle Composition and Distribution" (2004). Marine Sciences Faculty Scholarship. 87.

https://digitalcommons.library.umaine.edu/sms_facpub/87 
Authors

Emmanuel Boss, W. S. Pegau, M. Lee, M. Twardowski, E. Shybanov, G. Korotaev, and F. Baratange 


\title{
Particulate backscattering ratio at LEO 15 and its use to study particle composition and distribution
}

\author{
E. Boss,${ }^{1}$ W. S. Pegau, ${ }^{2}$ M. Lee, ${ }^{3}$ M. Twardowski, ${ }^{4}$ E. Shybanov, ${ }^{3}$ G. Korotaev, ${ }^{3}$ \\ and F. Baratange ${ }^{2}$
}

Received 20 June 2002; revised 6 May 2003; accepted 11 June 2003; published 21 January 2004

[1] Particulate scattering and backscattering are two quantities that have traditionally been used to quantify in situ particulate concentration. The ratio of the backscattering by particles to total scattering by particles (the particulate backscattering ratio) is weakly dependent on concentration and therefore provides us with information on the characteristics of the particulate material, such as the index of refraction. The index of refraction is an indicator of the bulk particulate composition, as inorganic minerals have high indices of refraction relative to oceanic organic particles such as phytoplankton and detrital material that typically have a high water content. We use measurements collected near the Rutgers University Long-term Ecosystem Observatory in $15 \mathrm{~m}$ of water in the Mid-Atlantic Bight to examine application of the backscattering ratio. Using four different instruments, the HOBILabs Hydroscat-6, the WETLabs ac-9 and EcoVSF, and a prototype VSF meter, three estimates of the ratio of the particulate backscattering ratio were obtained and found to compare well. This is remarkable because these are new instruments with large differences in design and calibration. The backscattering ratio is used to map different types of particles in the nearshore region, suggesting that it may act as a tracer of water movement. We find a significant relationship between the backscattering ratio and the ratio of chlorophyll to beam attenuation. This implies that these more traditional measurements may be used to identify when phytoplankton or inorganic particles dominate. In addition, it provides an independent confirmation of the link between the backscattering ratio and the bulk composition of particles. INDEX TERMS: 4552 Oceanography: Physical: Ocean optics; 4847 Oceanography: Biological and Chemical: Optics; 4294 Oceanography: General: Instruments and techniques; KEYWORDS: backscattering coefficient, backscattering ratio, Mid-Atlantic Bight, LEO 15, distribution of optical properties over a continental shelf

Citation: Boss, E., W. S. Pegau, M. Lee, M. Twardowski, E. Shybanov, G. Korotaev, and F. Baratange (2004), Particulate backscattering ratio at LEO 15 and its use to study particle composition and distribution, J. Geophys. Res., 109, C01014, doi:10.1029/2002JC001514.

\section{Introduction}

[2] An important problem in coastal oceanography is the lack of simple, in situ, techniques to study the composition of the oceanic particles. Knowledge of the particulate composition would provide an important input to sediment transport models as well as carbon flux estimates. Optical measurements of attenuation or backscattering have often been used to infer the concentration of material in the ocean [e.g., Jerlov, 1976], though the nature of the particulate could not be retrieved from such measurement. Recently, Twardowski et al. [2001] have shown that a combination of

\footnotetext{
${ }^{1}$ School of Marine Sciences, University of Maine, Orono, Maine, USA.

${ }^{2}$ College of Ocean and Atmospheric Sciences, Oregon State University, Corvallis, Oregon, USA.

${ }^{3}$ Marine Hydrophysical Institute, Sevastopol, Ukraine.

${ }^{4}$ Western Environmental Technology Laboratories Inc., Sauderstown, Rhode Island, USA.
}

Copyright 2004 by the American Geophysical Union. 0148-0227/04/2002JC001514 several optical measurements can be used to infer the bulk composition of the suspended particles. In the current paper we revisit this method and apply it in shallow coastal shelf waters.

[3] Light scattering by particles depends on the particle's size, index of refraction, composition, and shape [van de Hulst, 1981]. Measuring different aspects of scattering, such as its variation with wavelength (the spectrum), its variation with angle and its polarization properties have been found to provide information on the underlying particle's size, index of refraction, and shape [Bohren and Huffman, 1983].

[4] Light scattering is described by the volume scattering function (VSF, denoted by $\beta(\theta)$, where $\theta$ is the scattering angle measured from the forward direction, and assuming azimuthal symmetry) [e.g., Mobley, 1994]. The scattering coefficient (b) is the integral of the VSF over all scattering angles:

$$
b=2 \pi \int_{0}^{\pi} \beta(\theta) \sin (\theta) d \theta .
$$




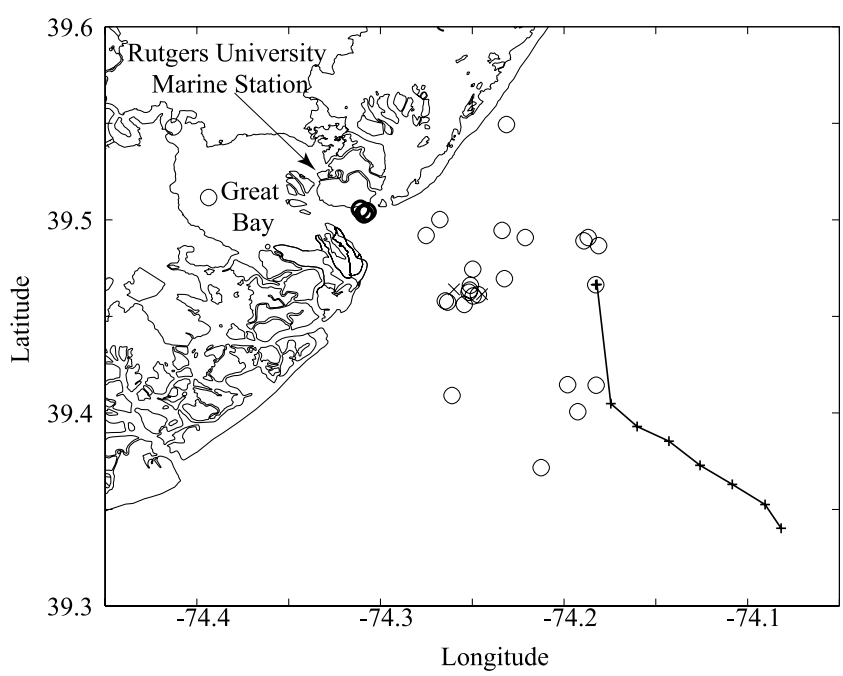

Figure 1. Location of stations sampled in July of 2000 (circles) at the New Jersey coast as well as the transect performed on 27 July 2000 (pluses). Crosses denote the position of the two nodes moorings of the LEO $15 \mathrm{ob}-$ servatory. Thick circles denote the shallow stations $(6 \mathrm{~m}>$ depth of water column $>2 \mathrm{~m}$ ) where the highest values of backscattering $(>0.03)$ were found.

The backscattering coefficient is similarly defined as

$$
b_{b}=2 \pi \int_{\pi / 2}^{\pi} \beta(\theta) \sin (\theta) d \theta .
$$

[5] Oceanic particles span a large range of indexes of refraction which are strongly related to the composition of the particles. Phytoplankton have low indices of refraction (n), (1.02-1.07, relative to water) [e.g., Carder et al., 1972] mainly because of high water fraction [Aas, 1996], while inorganic particles have a high index of refraction (1.11.26) [e.g., Carder et al., 1974; Aas, 1996; Lide, 1997]. While the indices of refraction change spectrally in the visible, these changes are small, except near strong absorption bands [e.g., Aas, 1996].

[6] Previous studies have found that the VSF can be inverted to study the bulk index of refraction of an ensemble of particles [Brown and Gordon, 1974; Roach, 1974; Zaneveld et al., 1974]. However, these inversions are not readily usable with current commercial optical instrumentation. Twardowski et al. [2001] used Mie theory, the theory that describes the interaction of light with homogeneous and spherical particles, to show that for realistic oceanic particle assemblages, the particulate backscattering ratio (the ratio of backscattering to total scattering by particles, $b_{b p} / b_{p}$ ) provides a proxy to the bulk index of refraction of the assemblage. They computed the index of refraction from the particulate backscattering ratio for observations from the Gulf of California and found the spatial distribution of the index of refraction to be consistent with expectation; blue waters were dominated by low index of refraction material, consistent with organic particles. In coastal waters they found the material near the bottom to have high index of refraction, consistent with inorganic particles.

[7] In the current paper we use the same technique as presented by Twardowski et al. [2001] in a coastal environ- ment to examine the particulate backscattering ratio distribution and its relation to other particulate optical properties such as chlorophyll absorption and particulate attenuation. Using three different estimates of the backscattering ratio with data from four different instruments we show the backscattering ratio to be robust, i.e., not strongly influenced by the technique used to measure the backscattering coefficient. Additionally, we demonstrate the use of the backscattering ratio as a tracer for particles, by highlighting particles that are distributed along a density front which are not clearly seen using other optical measurements. Finally, we show that the backscattering ratio is negatively correlated to the ratio of chlorophyll absorption to particulate beam attenuation. This correlation is a testimony to the relationship that exists between index of refraction and composition.

[8] The data analyzed here were collected in the vicinity of the Long-term Ecological Observatory (LEO) of Rutgers University on the New Jersey shelf, which is located in the Middle Atlantic Bight (Figure 1). The Mid-Atlantic Bight, because of its wide shallow shelf and high input of nutrients, has one of the largest productivity rates [Bourne and Yentsch, 1987; Sherman et al., 1996]. A large fraction of the in-water biogenic material sinks to the bottom and supports benthic microbial activity [Kemp, 1994]. Optically, such a region is interesting for several reasons: a) there exist large sources of organic and inorganic particles, b) The distribution of the particulate material is strongly influenced by advection as well as processes specific to particles (aggregation, sinking, swimming, growth), c) terrestrial sources of dissolved organic as well as particulate material add complexity to the interpretation of ocean color. Such a site provides a challenge to inversion algorithms designed to obtain particle properties from optical measurements. Chang et al. [2002], analyzed the variability of optical properties near LEO and related them to the underlying physics. They found the variability in optical properties to be dominated by the tides and the presence of a coastal density front with an associated geostrophic jet. Here we focus on a specific optical parameter, the backscattering ratio, its distribution and the additional information it provides for the of study particulate dynamics.

[9] This paper is organized as follows: (1) the different methods used to compute the particulate backscattering ratio (given the novelty of the instrumentation, we expand on these methods), (2) three different estimates of the backscattering ratio are then compared in order to increase our confidence in the data set, (3) different optical measurements are presented along a cross shore transect to highlight the informational content of the backscattering ratio in comparison to other, more commonly used optical parameters, (4) measurements of the backscattering ratio are applied to the model presented by Twardowski et al. [2001] to examine the bulk particulate composition, and (5) using the entire data set collected in 2000, a significant correlation between the backscattering ratio and the ratio of chlorophyll absorption to the particulate beam attenuation is shown.

\section{Methods}

\subsection{Scattering Measurements}

[10] The total scattering coefficient was estimated in two ways: 
[11] 1. Scattering was measured with a WETLabs ac-9. Attenuation and absorption coefficients were corrected for drift using pure water calibrations [Twardowski et al., 1999] and for changes in water absorption and attenuation due to temperature and salinity following Pegau et al. [1995]. A CTD was mounted on the package for this purpose. Dissolved absorption and attenuation was subtracted using simultaneous measurements with an ac-9 equipped with a $0.2 \mu \mathrm{m}$ filter [Twardowski et al., 1999]. Then the particulate absorption was corrected for scattering errors using the spectral scattering and the measured value at $715 \mathrm{~nm}$ (third method of Zaneveld et al. [1994]). Finally, particulate scattering is computed from the difference between attenuation and absorption:

$$
b_{p, a c-9}=c_{p, a c-9}-a_{p, a c-9}
$$

Since the acceptance angle of the beam transmissometer side of the ac- 9 is $0.7^{\circ}$, this scattering coefficient is smaller than that would be obtained with a transmissometer with a smaller aperture [Voss and Austin, 1993; Pegau et al., 1995]. Note, however, at smaller acceptance angles $\beta(\theta)$ (and hence $b$ ) may be influenced by turbulence, both natural and that caused by the instrument [e.g., Bogucki et al., 1998]. In our Mie modeling (see below) the finite acceptance angle is taken into account, and thus is not a source of error in the application of the model to the data.

[12] 2. The scattering coefficient was also determined from direct measurement of the VSF. A novel instrument for measuring the VSF between $0.6^{\circ}$ and $177.3^{\circ}$ at $0.3^{\circ}$ intervals [Lee and Lewis, 2003] was deployed. Given the measurement interval, we calculate the total scattering as:

$$
b_{V S M}=2 \pi \int_{0.6}^{177.3} \beta(\theta) \sin (\theta) d \theta+2 \pi \beta(177.3) \int_{177.3}^{180} \sin (\theta) d \theta .
$$

Thus we assume that the VSF does not change between 177.3 and $180^{\circ}$. This assumption has negligible effect on the following results as the second integral in the calculation of $b_{\mathrm{VSM}}$ contribute less than $0.03 \%$. The particulate scattering $\left(b_{p, V S M}\right)$ is obtained by subtracting the scattering by salt water following Morel [1974] (see below).

\subsection{Backscattering Measurements}

[13] The particulate backscattering coefficient was estimated as follows for three different instruments.

\subsubsection{Hydroscat-6 (HS-6, HOBILabs)}

[14] The HS-6 measures scattering at a single angle in the backward direction $\left(140^{\circ}\right)$ [Maffione and Dana, 1997] at six wavelengths. In this study we processed the data in the following way.

[15] 1. We obtain an estimate of $b_{b, 1}$ from HOBILabs software where calibration coefficients are applied. HS-6 calibrations are performed using a Lambertian reflecting plaque technique, where the signal response is measured through the sample volume [Maffione and Dana, 1997].

[16] 2. We correct for loss of photons along the path (R. Maffione, personal communication, 2001):

$$
b_{b, 2}=b_{b, 1} \sigma, \sigma=k_{0}+k_{1}(a+0.4 b)+k_{2}(a+0.4 b)^{2}
$$

The factor of 0.4 accounts for the fact that some forward scattered light is collected by the detector (R. Maffione, personal communication, 2001). It is based on Petzold's [1972] phase function measurements (NUC2040), where approximately $60 \%$ of total scattering was measured in the first $8^{\circ}$, the acceptance angle of the HS- 6 . The factors $k_{j}$ were provided by HOBILabs and are obtained by the calibration procedure. The error in this correction scheme is estimated to be $\pm 10 \%$ by R. Maffione (personal communication, 2001). This correction was done using $a$ and $b$ measured by the ac- 9 and was typically less than $15 \%$ of the signal.

[17] 3. We obtain VSF at $140^{\circ}$ :

$$
\beta\left(140^{\circ}\right)=b_{b, 2} /(2 \pi \cdot 1.08) .
$$

The factor 1.08.2 $\pi$, from Maffione and Dana [1997], was used by HOBILabs processing software to convert $\beta(140)$ to $b_{b}$. Dividing by this factor converts $b_{b}$ back to $\beta(140)$.

[18] 4. We subtract scattering by water to obtain particulate scattering [after Morel, 1974]:

$$
\beta_{\mathrm{p}}(\theta)=\beta(\theta)-\beta_{\mathrm{w}}(\theta),
$$

where $\beta_{\mathrm{w}}(\theta)=1.38(\lambda / 500 \mathrm{~nm})^{-4.32}(1+0.3 \mathrm{~S} / 37) 10^{-4} \cdot(1+$ $\left.\cos ^{2} \theta(1-\delta) /(1+\delta)\right) \mathrm{m}^{-1} \mathrm{Sr}^{-1}, \delta=0.09$. $\theta$ is the measurement angle $\left(140^{\circ}\right), \lambda$ is the wavelength, and $\mathrm{S}$ salinity, which was measured concurrently with a CTD.

[19] 5. We compute the backscattering coefficient of particles [Boss and Pegau, 2001]:

$$
b_{b p, H S}=2 \pi \cdot 1.18 \beta_{p}\left(140^{\circ}\right) \text {. }
$$

Note that this process differs from the procedure recommended by the manufacturer [Maffione and Dana, 1997] because separate conversion factors for $\beta$ to $b_{b}$ are used to account for differences in the VSF of water and particles [Boss and Pegau, 2001]. The method suggested by Boss and Pegau [2001] is more accurate because the proportional contribution of water to total volume scattering varies with changes in particle loads. Resulting errors from using a "totals" conversion become especially significant in clear waters. Recently (after July 2002) the water correction has been added to the manufacturer's software (D. Dana, personal communication, 2002).

\subsubsection{Eco-VSF (WetLabs)}

[20] The Eco-VSF measures scattering at three angles in the backward direction $\left(100,125\right.$, and $\left.150^{\circ}\right)$ at one wavelength. Data was processed in the following way.

[21] 1 . We obtain an estimate of $\beta_{p}(\theta)$ at the three angles using the Eco-VSF calibration file. ECO-VSF calibrations are performed using a numerical reduction analysis of the measurement geometry combined with measurements in microsphere solutions with known phase function [Moore et al., 2000]. WETLabs calibrations provide an engineering offset and a scaling factor, the latter derived from measurements in a serial concentration of microsphere solutions. In the calibration procedure that was used by WETLabs at the time of data collection, the engineering offsets (also known as the dark offsets) were estimated using the results from the measurements in microsphere solutions. The linear calibration regression between raw counts and b (as measured with 
an ac-9) was extrapolated to a baseline of $b=0.1 / \mathrm{m}$. This methodology has changed so that the dark offset is now measured independently. By implementing the original calibration procedure in the measurements here, it is assumed that scattering by fresh water is not included in the measurement. The current calibration procedure suggested by the manufacturer includes scattering by fresh water. Note, given the calibration procedure, using beads, the measured VSF, $\beta_{1 p}$, contains scattering by particles, as well as additional scattering due to salts in the seawater, but not fresh water.

[22] 2. We correct for loss of photons along the path:

$$
\beta_{2, p}(\theta)=\beta_{1, p}(\theta) \exp \left(a_{p g} L\right),
$$

where $\mathrm{L}$ represents a nominal path length obtained by a numerical integrating procedure using the geometry of the measurement $\left(0.0314,0.0441\right.$, and $0.0804 \mathrm{~m}$ for $100^{\circ}, 125^{\circ}$, and $150^{\circ}$, respectively (J. R. V. Zaneveld, personal communication, 2001)). This correction is only done with absorption by particulate and dissolved materials, $a_{p g}$, assuming that scattering losses and absorption by water are well represented by the calibration procedure. This correction was done using the ac-9 measurement and was typically less than $5 \%$ of the signal.

[23] 3. We compute total bb from the beta measurements at three angles. Fit a third-order polynomial through all the measurements points of $\left(2 \pi \beta_{p}(\theta) \sin \theta\right)$, including $\theta=\pi$, where $\beta_{p}(\pi) \sin \pi=0$. Integrate the area under the polynomial to estimate the particulate backscattering coefficient $b_{b p, \mathrm{ECO}}^{\prime}$ [Moore et al., 2000].

[24] 4. We obtain the backscattering by particles by subtracting scattering by salts [after Morel, 1974]:

$$
\mathrm{b}_{\mathrm{bp}, \mathrm{ECO}}=\mathrm{b}_{\mathrm{bp}, \mathrm{ECO}}^{\prime}-\mathrm{b}_{\mathrm{bs}},
$$

where $b_{b s}=8.03((1.41-1.08) \cdot S / 37) \cdot 10^{-4}$ for $\lambda=530 \mathrm{~nm}$.

\subsubsection{Volume Scattering Meter (VSM, 530 nm)}

[25] In the backward, the VSM measures beta from 90 to 177.3 degrees at 0.3 degree intervals. The instrument is calibrated by theoretical analysis of the measurement geometry coupled with measurements of microsphere solutions with known phase function [Lee and Lewis, 2003]. The measurements were corrected for attenuation along the path length using the ac-9 data.

[26] The backscattering coefficient was determined by integrating the phase function over the measurement range:

$b_{b p, V S M}=2 \pi \int_{90}^{177.3} \beta(\theta) \sin (\theta) d \theta+2 \pi \beta(177.3) \int_{177.3}^{180} \sin (\theta) d \theta-b_{b s w}$

where $b_{b s w}=8.03 \cdot(1.08+(1.41-1.08) \cdot \mathrm{S} / 37) \cdot 10^{-4}$ for $\lambda=$ $530 \mathrm{~nm}$. In the second integral it is assumed that the VSF stays constant from $177.3^{\circ}$ to $180^{\circ}$. This assumption has little effect on the results as the second integral contributes only $\mathrm{O}(1 \%)$ to $b_{b p, V S M}$.

\subsection{Backscattering Ratios}

[27] In this paper we concentrate on the particulate backscattering ratio and not on the backscattering coeffi- cient or the scattering coefficient per se. We estimated the backscattering ratio from the above described measurements in three ways:

$$
\begin{gathered}
\tilde{b}_{V S M}=\frac{b_{b p, V S M}}{b_{p, V S M}} \\
\tilde{b}_{H S}=\frac{b_{b p, H S}}{b_{a c-9}} \\
\tilde{b}_{E C O}=\frac{b_{b p, E C O}}{b_{a c-9}}
\end{gathered}
$$

\subsection{Chlorophyll to Beam Attenuation Ratio}

[28] In this work we do not have any direct estimates of bulk refractive index. In order to increase our confidence in the inversion we use another ratio of two optically retrievable parameters, the ratio of [chl] to the particulate beam attenuation at $650 \mathrm{~nm}, c_{p}(650)$.

[29] Chlorophyll a concentration ([chl]) was computed from absorption of particulate and dissolved $\left(a_{\mathrm{pg}}\right)$ using the relationship developed by $\mathrm{C}$. Roesler (personal communication, 2000):

$$
[c h l]=\left(a_{p g}(676)-a_{p g}(650)\right) / 0.014
$$

This relationship derives the chlorophyll concentration $\left(\mu \mathrm{g} \mathrm{L}^{-1}\right)$ by dividing its absorption by a chlorophyll specific absorption at $676 \mathrm{~nm}$ assumed to be of $0.014 \mu \mathrm{gr} \mathrm{L}^{-1} \mathrm{~m}^{-1}$. This relationship has been found to have a close fit with chlorophyll a obtained through traditional extraction methods with data off the Oregon coast $\left(r^{2}=0.98\right.$, where $r^{2}$ denotes the square of the correlation coefficient) (L. KarpBoss, personal communication, 2001). Chang et al. [2000] found it to correlate well with in situ chlorophyll fluorescence $\left(\mathrm{r}^{2}=0.92\right)$ near our sampling site and for the same period. It is a variance of the spectrophotometric method used for an ac-3 by Davis et al. [1997]. This relationship is likely to deteriorate in situations where chlorophyll concentrations are low and the particulate absorption is dominated by absorbing detrital and inorganic particles. Also, chlorophyll specific absorption at 676 is not constant and varies between 0.007 and 0.021 for phytoplankton [Bricaud et al., 1995].

[30] Chlorophyll $a$ is a phytoplankton specific pigment that has been used has a pragmatic surrogate to phytoplankton biomass [e.g., Falkowski and Raven, 1997]. In stable water columns, chlorophyll concentration per cell can vary by as much as a factor of 10 [e.g., Falkowski and Raven, 1997] because of phytoplankton photoadaptation. The absorption by chlorophyll, however, varies less because of the packaging of the chlorophyll [Falkowski and Raven, 1997]. The beam attenuation per cell at $650 \mathrm{~nm}$ is likely not to be affected much by this chromatic adaptation [e.g., Boss et al., 2001b]. Changes in beam attenuation of the phytoplankton fraction due to swelling, growth, and storage are likely to be less than 30\% [Cullen and Lewis, 1995]. Beam attenuation by particles has been found to be a good proxy of particulate concentration and volume [e.g., Baker and Lavelle, 1984, and references therein]. Since the beam attenuation per volume is a function of index of refraction [e.g., Boss et al., 2001b, Figure 6] it will be skewed toward the refractive fraction of a particulate assemblage. 
[31] To first order, however, the ratio of [chl] to beam attenuation is indicative of the proportion of phytoplankton concentration to the total particulate concentration. Presence of organic detritus will contribute to the particulate beam attenuation, but, given their less refractive nature, with less contribution per volume than that of inorganic particles. The backscattering ratio of detritus is unknown and was discussed at length by Twardowski et al. [2001].

\subsection{Estimation of the Hyperbolic Slope of the Particulate Size Distribution From the Attenuation Spectra}

[32] Beam attenuation slopes, $\gamma$, were computed from $c_{p}$ spectra using the following relationship [e.g., Boss et al., 2001a, 2001b]:

$$
c_{p}=c_{p}\left(\lambda_{0}\right)\left(\frac{\lambda}{\lambda_{0}}\right)^{-\gamma}
$$

These slopes were used as input to the refractive index model, along with backscattering ratios, as described by Twardowski et al. [2001]. Beam attenuation slopes covary with hyperbolic particle size distribution (PSD) slopes in theory [Boss et al., 2001a] and in measurement [Boss et al., 2001b; Oubelkheir, 2001], and are thus expected to account for general changes in particle size distribution shapes in the model.

[33] In Twardowski et al.'s [2001] study, the relationship used between the hyperbolic slope of the PSD, $\xi$, and $\gamma$ was $\xi=\gamma+3$. For the more general case of hyperbolic PSDs with finite limits, however, Boss et al. [2001a] found the following relationship to be more accurate: $\xi=\gamma+3-0.5 \exp (-6 \gamma)$. This updated relationship is used to estimate $\xi$ as input to the model here. The correction is important for flat PSDs as encountered, for example, in bottom boundary layers.

[34] Boss et al. [2001a] show that beam attenuation is most affected by particles with sizes spanning from 0.5 to $10 \mu \mathrm{m}$ (their beam c/volume is maximal at this range). Thus it is the PSD in this region that we care most about. We do not expect and do not assume that a hyperbolic PSD is valid for particles far out of this range.

\subsection{Mie Calculations for the Index of Refraction Model}

[35] We recalculated the model by Twardowski et al. [2001] that relates the index of refraction to the backscattering ratio and the slope of the hyperbolic size distribution. We used Mie theory which assumes spherical homogeneous particles. The code we used is a Matlab translation of the 'bhmie' program of Bohren and Huffman [1983]. The output VSF had a resolution of $0.3^{\circ}$. We numerically integrated it, similar to VSM data, using a high order $\left(1 / \mathrm{N}^{4}\right)$ extended formula provided by Press et al. [1992]. Particles sizes spanned from 0.01 to $300 \mu \mathrm{m}$. The contribution of the $0.01-0.2 \mu \mathrm{m}$ size range to total particulate scattering was found to be negligible in its effect on the theoretical backscattering ratio (for which particulate scattering was based on the fraction bigger than $0.2 \mu \mathrm{m}$ ). Particles ensembles were assumed to be of the same index of refraction and distributed hyperbolically.

\subsection{Deployment Method}

[36] The HS-6, Eco-VSF (532 nm), and ac-9s were attached to a slow decent rate optical profiler (SlowDROP), to ensure slow and monotonic profiling. Before $7 / 23 / 00$, the VSM was deployed over the side of the vessel, and afterward by pumping water from the SlowDROP to the VSM via a hose. By pumping water we ensured that all instruments sampled the same water. It also extended the depth range of the VSM.

\subsection{Data Reduction}

[37] The data analyzed here include 153 data sets containing simultaneous measurements with HS-6, Eco-VSF, and ac-9s, taken either as a time series at a given depth or as profiles. All the data were binned to $0.5 \mathrm{~m}$, resulting in 3216 measurements of each property. In 44 cases we obtained measurement matchups between the SlowDROP and the VSM (same time and approximately same depth).

\section{Results}

\subsection{Backscattering Ratio Intercomparison}

[38] To help constrain the accuracies in our estimates of backscattering ratios, used here to compute the particulate refractive indices, the measurements made with different methodologies were compared.

[39] A data set of 44 comparisons of the particulate backscattering ratio was compiled (Figure 2). The correlation coefficient between the $\tilde{b}_{H S}$ and $\tilde{b}_{E C O}$ estimate was very high $\left(\mathrm{r}^{2}=0.99\right)$ with the $\tilde{b}_{E C O}$ being on average $1.5 \%$ higher. Correlation between $\tilde{b}_{H S}$ or $\tilde{b}_{E C O}$ with VSM estimate was worse $\left(\mathrm{r}^{2}=0.88\right)$ with the VSM being on average $10 \%$ higher in magnitude. Closer examination of Figure 2 shows that the correlation between the VSM estimate and the other techniques improved with time (for the data after matchup $\left.25, \mathrm{r}^{2}=0.97\right)$. Two factors contributed to this improvement; a) closer matching of measurement depths and times and b) pumping of water from the SlowDROP to the VSM (started at matchup point 24). After sample 14 the three backscattering estimates are within \pm 0.003 (Figure 2). Given the large dynamic range of observed backscattering ratios $(0.005-$ 0.035 ) we conclude that instrumental closure has been achieved with uncertainties generally on the order of $10 \%$. The backscattering ratio varies by a factor of 4-6 between phytoplankton and inorganic sediment [Twardowski et al., $2001]$ and errors of $\mathrm{O}(10 \%)$ in the backscattering ratio will not introduce significant uncertainties in the inversion of the backscattering ratio to obtain the bulk index of refraction. Given the high correlation between the different backscattering estimates, we arbitrarily chose to describe the spatial distribution of backscattering ratio using $\tilde{b}_{H S}$, and the temporal distribution of backscattering ratio using $\tilde{b}_{E C O}$, and investigated their relation to other optical and physical measurements.

\subsection{Distributions of Backscattering Ratio and Its Relation to Other Measurements}

[40] Distributions of inherent optical properties and hydrographic properties were collected along a transect perpendicular to the New Jersey coast (Figure 3). Close to the coast, a phytoplankton bloom dominated the near surface optical properties. A front in optical properties was observed at the edge of the bloom at about $5 \mathrm{~km}$ into the across-shore transect, separating the bloom from relatively clearer waters. The analysis of the interaction of physical and bio-optical properties giving rise to the 


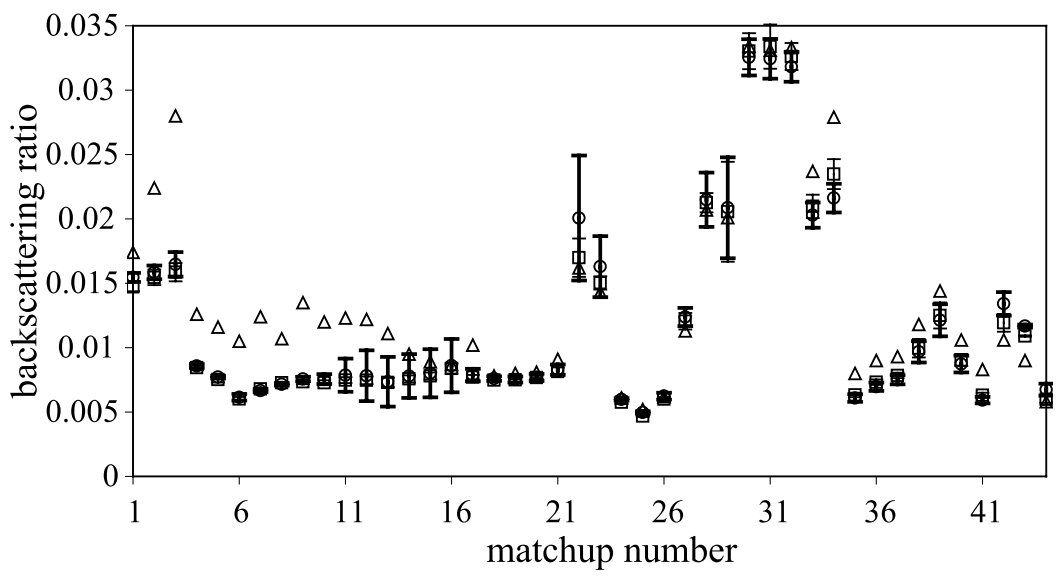

Figure 2. Comparison of 44 chronologically arranged matchups of particulate backscattering ratios near $532 \mathrm{~nm}$. VSM-based backscattering ratios are denoted by triangles, HS-6/ac-9 by squares, and Eco-VSF/ ac- 9 by circles. Thick error bars are associated with the Eco-VSF, while thin error bars are associated with the HS-6 measurements and are based on the standard deviation of the variables over measurements collected at a fixed depth.

observed front was published elsewhere [Chang et al., 2002]. Here we focus on the added information provided by the backscattering ratio.

[41] The same general pattern was observed in both the distributions of particulate beam attenuation and [chl] (Figure 3b). The two are found to be very well correlated along this transect $\left(r^{2}=0.96\right)$, while for the whole data set the correlation between them was poor $\left(r^{2}=0.13\right)$. An additional near-bottom turbid layer extending from the bottom to about $10 \mathrm{~m}$ above bottom was visible in the distribution of backscattering (Figure 3c).

[42] The backscattering ratio $\left(b_{H S}\right.$; Figure $\left.3 \mathrm{~d}\right)$ was distributed differently than the beam attenuation, backscattering or [chl]. The surface front was not observed in the backscattering ratio, and the surface values were uniformly low $(\sim 0.006)$, consistent with dominance of the particle field by low refractive index particles such as phytoplankton. The backscattering ratio increased monotonically with depth almost everywhere, consistent with an increase in inorganic material with depth. A relatively high vertical gradient in the backscattering ratio was coincident with the pycnocline (Figure 3e). Notice that this gradient layer (where $0.008<\tilde{b}_{H S}<0.015$ ) is only weakly observed in the attenuation (an increase of less than $0.3 \mathrm{~m}^{-1}$ above background) and that strongest vertical gradients in beam attenuation and [chl] occurred higher up around $8 \mathrm{~m}$.

\subsection{Backscattering Ratio and the Index of Refraction}

[43] Contours of bulk index of refraction for the whole data set are plotted as a function of the particulate backscattering ratio and the exponent of the particulate size distribution (Figure 4). These contours are derived from Mie calculations [Twardowski et al., 2001] (see section 2). The computations were also recomputed for the case of nonabsorbing particles, $n^{\prime}=0$ (Figure 4a) as well as $n^{\prime}=0.005$ (Figure 4b), as in the Twardowski et al. study). $n^{\prime}$ is the imaginary part of the index of refraction, which is proportional to absorption for material when dissolved. We overlayed these plots with the same binned measurements of the backscattering ratio and the estimated Junge-like slope of the PSD. We chose two inversions with different $n^{\prime}$ to highlight the influence of $n^{\prime}$ on the inversion, particularly for particles with large indices of refraction (see discussion below). Spectral variation between 440 and $620 \mathrm{~nm}$ in $\tilde{b}_{H S}$ varied by less than $10 \%$ for all values of backscattering, as predicted from theory [Ulloa et al., 1994; Twardowski et al., 2001].

[44] The values of the estimated bulk index of refraction span the full range expected for phytoplankton $(n \approx 1.02-$ 1.05) to inorganic particles such as quartz and aragonite $(n \approx 1.15$ - 1.24) [e.g., Aas, 1996; Carder et al., 1974]. Indeed, the highest values were observed during a time series obtained in $5 \mathrm{~m}$ deep waters near a beach, while the lowest values were coincident with high [chl] content.

[45] In this work we do not have any direct estimates of bulk refractive index. In order to increase our confidence in the inversion we use another ratio of two optically retrievable parameters, the ratio of [chl] to $c_{p}(650)$. We find that the backscattering ratio to be negatively correlated with the $[\mathrm{chl}] / c_{p}$ (Figure 5), with a correlation coefficient, $\mathrm{r}=-0.75$ $\left(\mathrm{r}=0.73\right.$ for $\left.\mathrm{c}_{\mathrm{p}} /[\mathrm{chl}]\right)$. Low $[\mathrm{chl}] / \mathrm{c}_{\mathrm{p}}$ ratio is indicative relatively low concentration of phytoplankton and is consistent with high refractive material (relatively large contribution from inorganic particles) while a high $[\mathrm{chl}] / \mathrm{c}_{\mathrm{p}}$ ratio indicate domination of the particulate by phytoplankton and is consistent with low refractive material (low backscattering ratio). Notice that our (relatively) tight relationship is largely due to the large dynamic range in our measurements. Changes of $[\mathrm{chl}] / \mathrm{c}_{\mathrm{p}}$ due to chromatic adaptation are likely the cause of the large range in $[\mathrm{chl}] / \mathrm{c}_{\mathrm{p}}$ values for the low values of $b_{b p} / b_{p}$.

\section{Discussion and Conclusion}

[46] We have shown, through the use of four instruments, and three estimates of the backscattering ratio, that the latter can be computed routinely for the waters sampled in this study within approximately \pm 0.003 . The backscattering ratio intercomparison has never been attempted, and suggests that the current technology is nearing maturity. In addition, the large dynamic range in the particulate back- 

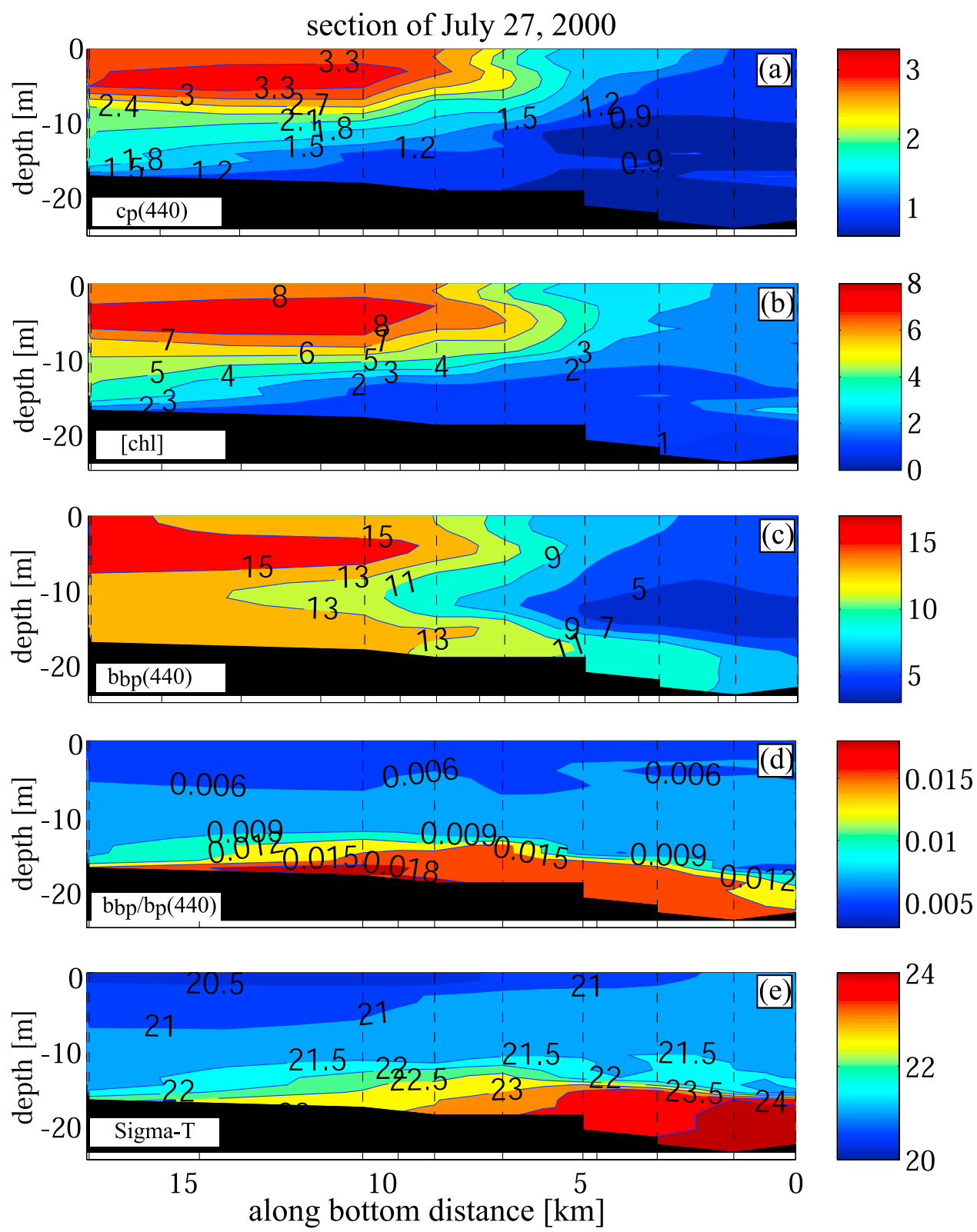

Figure 3. Distribution of (a) beam attenuation at $440 \mathrm{~nm}\left(\mathrm{~m}^{-1}\right)$, (b) chlorophyll a concentration ( $\mu$ gr L $\mathrm{L}^{-1}$ ), (c) backscattering at $440 \mathrm{~nm}\left(\mathrm{~m}^{-1}\right)$, (d) backscattering ratio at $440 \mathrm{~nm}$, and (e) density $\left(\mathrm{Kg} \mathrm{m}^{-3}-1000\right)$, along a transect off the Tuckerton shore, New Jersey (see Figure 1).

scattering ratio (about a factor of seven), suggest that errors of $\mathrm{O}(20 \%)$ either the value of scattering or backscattering are not likely to alter the inversion to obtain the bulk index of refraction of the particle assemblage.

[47] Twardowski et al. [2001] found that for low index of refraction particles $(n=1.05)$ the inversion to obtain the index of refraction is not very sensitive to absorption [see also Ulloa et al., 1994]. Here we found that the same inversion is sensitive to absorption for highly refractive particles when PSD slopes are less than about 3.5 (Figure 4a versus $4 \mathrm{~b}$ ). Therefore, without additional information on bulk particulate absorption, the inversion model is limited in its ability to retrieve the bulk index of refraction of particle populations dominated by highly refractive, relatively large particles, to within $\pm \mathrm{O}(0.02)$. Such particles can be expected to be present in coastal regions in water with recently resuspended sediments.

[48] It is difficult at this time to estimate reasonable absorption characteristics for surface sediments. Inorganic particles that may be present in coastal and oceanic sediments have been found to have a range of four orders of magnitudes in the magnitude of the imaginary part of their index of refraction at a given wavelength [e.g., Egan and Hilgeman, 1989; Lide, 1997]. Measurements (direct or through inference from related measurements) of the bulk $n^{\prime}$ of the mixed mineral component in natural waters have, however, generally fallen in the much narrower range of about 0.002 to 0.01 [Bukata et al., 1995; Tassan and Ferrari, 1995; Bowers et al., 1996]. This agrees well with the bulk $n^{\prime}$ found for airborne minerals likely to enter the 

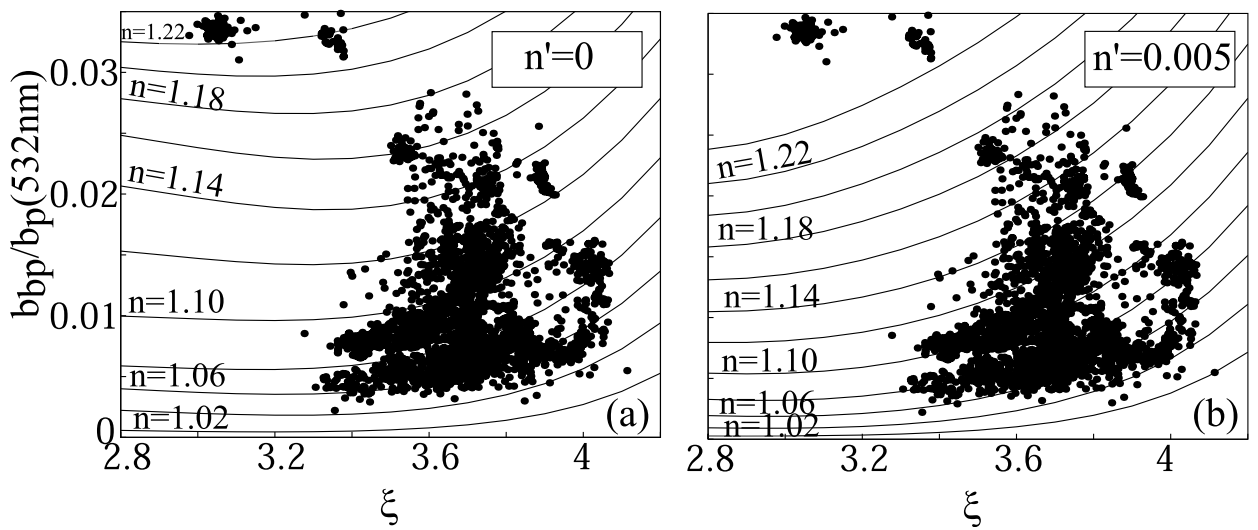

Figure 4. Estimated bulk refractive indices as function of the backscattering ratio and estimated hyperbolic particle size distribution slope for O(3200) $0.5 \mathrm{~m}$ bin data collected near LEO 15: inversion (a) assumes nonabsorbing particles $\left(\mathrm{n}^{\prime}=0\right)$ while (b) assumes $\mathrm{n}^{\prime}=0.005$.

ocean via atmospheric deposition [Grams et al., 1974; Lindberg and Laude, 1974; Patterson et al., 1977]. Despite these estimates, it is nonetheless possible that certain sediment strata may be dominated by minerals with very low $n^{\prime}$; for example, some clay minerals have $\mathrm{n}^{\prime}$ values less than 0.0001 [Egan and Hilgeman, 1979]. Therefore, $n^{\prime}$ values as low as 0.00015 , as recently used in a bulk optical model by Stramski et al. [2001], may also be applicable in certain cases. Moreover, the absorption by different surface sediments constitutes an important gap in our current knowledge of the optical properties of particles in coastal regions. Thus an uncertainty of $\pm \mathrm{O}(0.02)$ is inherent to our inversion for large index of refraction material. Such an uncertainty, however, does not limit our ability to differentiate waters dominated by phytoplankton $(\mathrm{n} \sim 1.04)$ and inorganic sediments $(n>1.15)$.

[49] Another limitation of our model is in our assumption of a Junge-like PSD model. Deviation from this model may contribute to errors in the inversion. Note, however, that using a more realistic PSD [after Risovic, 1993], we have found similar results to the inversion for relatively flat hyperbolic distributions $(\xi \sim 0)$ [Twardowski et al., 2001, Figure 1]. Another limitation is our use of a model with a single index of refraction and particulate size distribution rather than a model comprised of several particle population each with its own index of refraction [e.g., Zaneveld et al., 1974]. Luckily, the retrieval of the index of refraction is relatively insensitive, in most environments, to the PSD slope (Figure 4) or model [Twardowski et al., 2001].

[50] Despite the above limitation of the model in providing a tight range for estimating the index of refraction of highly refractive inorganic particles, it does appear to provide a robust differentiation between particles with different bulk composition (Figures 4 and 5). In particular, given that there is currently no in situ method to differentiate between bulk particulate compositions, uncertainties of $\mathrm{O}(0.02)$ in $n$ for refractive particles are not significant. It will, however, be limiting for a study of the composition of resuspended bottom sediment, if the aim is to differentiate between Calcite $(\mathrm{n}=1.19)$ and Aragonite $(\mathrm{n}=1.23)$

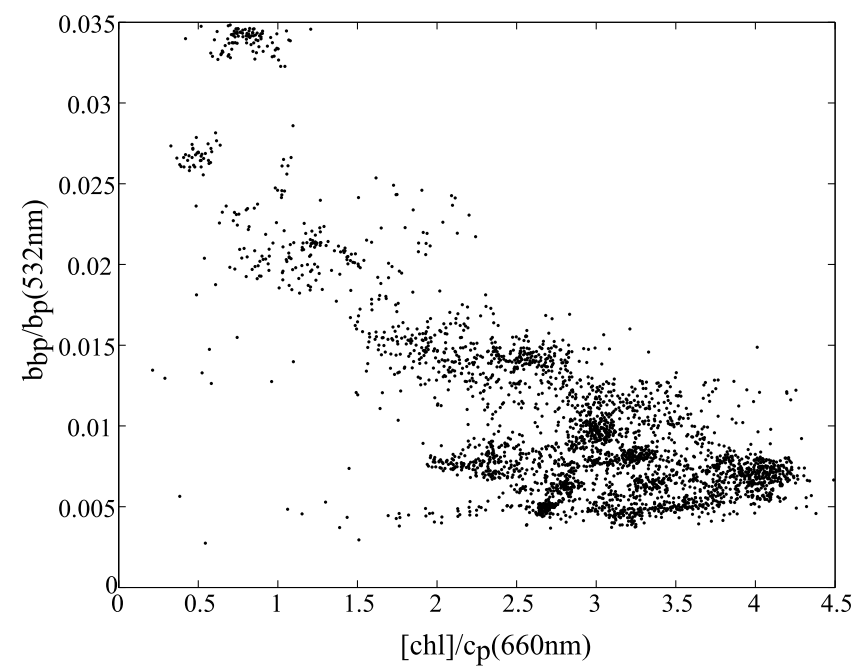

Figure 5. Backscattering ratio at $532 \mathrm{~nm}$ versus the ratio of chlorophyll to beam attenuation $(660 \mathrm{~nm})$ based on more than $31000.5 \mathrm{~m}$ binned data points. The correlation coefficient is $\mathrm{r}=-0.75$. The linear (type II) $\left[\right.$ Laws, 1997] regression line is $\mathrm{b}_{\mathrm{bp}}=-0.0066(\mathrm{SD}=0.0001)[\mathrm{chl}] / \mathrm{c}_{\mathrm{p}}(660)+0.0259(\mathrm{SD}=$ $0.0002)$. 
[Carder et al., 1974], unless absorption properties of the inorganic fraction were measured as well.

[51] The data set presented here provides evidence to the usefulness of the backscattering ratio as a biogeochemical particulate tracer. Its distribution is different then traditional optical measurement, providing novel information about processes affecting the particulate material and its distribution. Traditionally, both backscattering devices and beam transmissometers have been used to quantify the concentration of particulate material. The data presented here (e.g., Figures $3 \mathrm{a}$ and $3 \mathrm{c}$ ) highlight the differences in information contained in each of these measurements in areas where the particles properties (in particular the index of refraction) vary in space and time. Backscattering is more sensitive to the index of refraction than is the beam attenuation (their ratio varies a factor of 7 between low and high index of refraction particles; Figure 4), and we therefore observed a stronger signal of the refractive sediment particles in the particulate backscattering. The ratio of backscattering to beam attenuation of particles removes the effects of concentration, and provides information regarding particulate composition.

[52] Besides the theoretical relationship of the backscattering ratio with the bulk index of refraction, it is found here to be negatively correlated with the [chl] to beam attenuation ratio. This relationship provides an empirical support to the inversion between the index of refraction and the backscattering ratio. While such a correlation is not surprising in a shallow coastal environment during phytoplankton blooms we caution the readers that it may fail in environments dominated by detrital material or in water masses where phytoplankton photoadaptation varies significantly with respect to the $[\mathrm{chl}] /$ cell ratio. Since [chl] and beam attenuation are often the only optical properties measured in coastal monitoring programs, our data suggest that they could be used to estimate the bulk particulate composition.

[53] In summary, using four different instruments, three estimates of the ratio of the particulate backscattering ratio were obtained and found to compare well. The backscattering ratio is found to have informational content not easily seen in either attenuation, backscattering, or [chl]. Finally, by relating the backscattering ratio to the ratio of [chl] to beam attenuation an additional link between particle composition and the backscattering ratio was established.

[54] Acknowledgments. Thanks to A. Weidemann and G. Chang for insightful comments that have, together with comments by an anonymous reviewer, improved an earlier version of this paper. This work was supported by the Environmental Optics division of the Office of Naval Research as part of the Hyperspectral Coastal Ocean Dynamics Experiments (HyCODE).

\section{References}

Aas, E. (1996), Refractive index of phytoplankton derived from its metabolite composition, J. Plankton Res., 18, 2223-2249.

Bader, H. (1970), The hyperbolic distribution of particle sizes, J. Geophys. Res., 75, 2822-2830.

Baker, E. T., and J. W. Lavelle (1984), The effect of particles size on the light attenuation coefficient of natural suspension, J. Geophys. Res., 75 , 8197-8203

Bogucki, D. J., J. Domaradzki, D. Stramski, and J. R. V. Zaneveld (1998), Comparison of near-forward light scattering on oceanic turbulence and particles, Appl. Opt., 37, 4669-4677.

Bohren, C. J., and D. R. Huffman (1983), Absorption and Scattering of Light by Small Particles, 530 pp., John Wiley, Hoboken, N. J.
Boss, E., and W. S. Pegau (2001), The relationship of light scattering at an angle in the backward direction to the backscattering coefficient, Appl. Opt., 40, 5503-5507.

Boss, E., M. S. Twardowski, and S. Herring (2001a), The shape of the particulate beam attenuation spectrum and its relation to the size distribution of oceanic particles, Appl. Opt., 40, 4885-4893.

Boss, E., W. S. Pegau, W. D. Gardner, J. R. V. Zaneveld, A. H. Barnard, M. S. Twardowski, G. C. Chang, and T. D. Dickey (2001b), The spectral particulate attenuation and particle size distribution in the bottom boundary layer of a continental shelf, J. Geophys. Res., 106, 9509-9516.

Bourne, D. W., and C. S. Yentsch (1987), Phytoplankton, primary production, and microbiology, in Georges Bank, edited by R. H. Backus, pp. 210-212, MIT Press, Cambridge, Mass.

Bowers, D. G., G. E. L. Harker, and B. Stephan (1996), Absorption spectra of inorganic particles in the Irish Sea and their relevance to remote sensing of chlorophyll, Int. J. Remote Sens., 17, 2449-2469.

Bricaud, A., M. Babin, A. Morel, and H. Claustre (1995), Variability in the chlorophyll-specific absorption coefficients of natural phytoplankton: Analysis and parametrization, J. Geophys. Res., 100, 13,321-13,332.

Brown, O. B., and H. R. Gordon (1974), Size-refractive index distribution of clear coastal water particulates from light scattering, Appl. Opt., 13, 2874-2881.

Bukata, R. P., J. H. Jerome, K. Y. Kondratyev, and D. V. Pozdnyakov (1995), Optical Properties and Remote Sensing of Inland and Coastal Waters, CRC Press, Boca Raton, Fla.

Carder, K. L., R. D. Tomlinson, and G. F. Beardsley Jr. (1972), A technique for the estimation of indices of refraction of marine phytoplankters, Limnol. Oceanogr., 17, 833-839.

Carder, K. L., P. R. Betzer, and D. W. Eggimann (1974), Physical, chemical, and optical measures of suspended particle concentrations: Their intercomparison and application to the west African shelf, in Suspended Solids in Water, edited by R. J. Gibbs, pp. 173-193, Plenum, New York.

Chang, G. C., Jiang, X. Yu, S. Zedler, D. Manov, D. Sigurdson, F. Spada, and T. Dickey (2000), Data report: Hyperspectral Coastal Ocean Dynamics Experiment (HyCODE) deployment II: 25 July-15 September 2000, Ocean Phys. Lab. Tech. Rep. OPL-05-00, 42 pp., Ocean Phys. Lab., Univ. of Calif., Santa Barbara.

Chang, G. S., T. D. Dickey, O. M. Schofield, A. D. Weidemann, E. Boss, W. S. Pegau, M. A. Moline, and S. M. Glenn (2002), Nearshore physical processes and bio-optical properties in the New York Bight, J. Geophys. Res., 107(C9), 3133, doi:10.1029/2001JC001018.

Cullen, J. J., and M. R. Lewis (1995), Biological processes and optical measurements near the sea surface: Some issues relevant to remote sensing, J. Geophys. Res., 100, 13,255-13,266.

Davis, R. F., C. C. Moore, J. R. V. Zaneveld, and J. M. Napp (1997), Reducing the effects of fouling on chlorophyll estimates derived from long-term deployments of optical instruments, J. Geophys. Res., 102, $5851-5855$

Egan, W. G., and T. W. Hilgeman (1979), Optical Properties of Inhomogeneous Materials, Academic, San Diego, Calif.

Falkowski, P. G. and J. Raven (1997), Aquatic Photosynthesis, 375 pp., Blackwell, Malden, Mass.

Grams, G. W., I. H. Blifford Jr., D. A. Gillette, and P. B. Russell (1974), Complex index of refraction of airborne soil particles, J. Appl. Meteorol, $13,459-471$

Jerlov, N. G. (1976), Marine Optics, 231 pp., Elsevier Sci., New York.

Kemp, P. F. (1994), Microbial carbon utilization on the continental shelf and slope during the SEEP-II experiment, Deep Sea Res., Part II, 41, $563-581$.

Laws, E. (1997), Mathematical Methods for Oceanographers, John Wiley, Hoboken, N. J.

Lee, M. E., and M. R. Lewis (2003), A new method for the measurement of the optical volume scattering function in the upper ocean, J. Atmos. Oceanic Technol., 20, 563-571.

Lide, D. R., (Ed.) (1997), Physical and optical properties of minerals, in CRC Handbook of Chemistry and Physics, 77th ed., pp. 4.130-4.136, CRC Press, Boca Raton, Fla.

Lindberg, J. D., and L. S. Laude (1974), Measurements of the absorption coefficient of atmospheric dust, Appl. Opt., 13, 1923-1927.

Maffione, R. A., and D. R. Dana (1997), Instruments and methods for measuring the backward-scattering coefficient of ocean waters, Appl. Opt., 36, 6057-6067.

Mobley, C. D. (1994), Light and Water: Radiative Transfer in Natural Waters, 592 pp., Academic, San Diego, Calif.

Morel, A. (1974), Optical properties of pure water and pure seawater, in Optical Aspects of Oceanography, edited by N. G. Jerlov and E. S. Nielson, pp. 1-24, Academic, San Diego, Calif.

Oubelkheir, K. (2001), Caractérisation biogéochimique de provinces océaniques à l'aide d'indicateurs bio-optiques, à diverses échelles spatio-tem- 
porelles, Ph.D. thesis, 372 pp., Univ. de la Mediterranee, Marseille, France.

Patterson, E. M., D. A. Gillette, and B. H. Stockton (1977), Complex index of refraction between 200 and $700 \mathrm{~nm}$ for Saharan aerosols, J. Geophys. Res., 82, 3153-3160.

Pegau, W. S., J. R. V. Zaneveld, and K. J. Voss (1995), Toward closure of the inherent optical properties of natural waters, J. Geophys. Res., 100, $13,193-13,199$

Petzold, T. J. (1972), Volume Scattering Functions for Selected Ocean Waters, SIO Ref. $72-78,79$ pp., Scripps Inst. of Oceanogr., La Jolla, Calif.

Press, W. H., S. A. Teukolsky, W. T. Vetterling, and B. P. Flannery (1992), Numerical Recipes in $C$, 2nd ed., Cambridge Univ. Press, New York.

Risovic, D. (1993), Two-component model of sea particle size distribution, Deep Sea Res., Part I, 40, 1459-1473.

Roach, D. M. (1974), Determination of the refractive index distributions for oceanic particulates, Ph.D. thesis, 172 pp., Oregon State Univ., Corvallis.

Sherman, K., M. Grosslein, D. Mountain, D. Busch, and R. Theroux (1996), The northeast shelf ecosystem: An initial perspective, in The Northeast Shelf Ecosystem, edited by K. Sherman, N. A. Jaworski, and T. J. Samayda, pp. 103-126, Blackwell Sci., Malden, Mass.

Stramski, D., A. Bricaud, and A. Morel (2001), Modeling the inherent optical properties of the ocean based on the detailed composition of the planktonic community, Appl. Opt., 40, 2929-2945

Tassan, S., and G. M. Ferrari (1995), An alternative approach to absorption measurements of aquatic particles retained on filters, Limnol. Oceanogr., 40, $1358-1368$

Twardowski, M., E. Boss, J. B. Macdonald, W. S. Pegau, A. H. Barnard, and J. R. V. Zaneveld (2001), A model for estimating bulk refractive index from the optical backscattering ratio and the implications for understanding particle composition in case I and case II waters, J. Geophys. Res., 106, 14,129-14,142.

Twardowski, M. S., J. M. Sullivan, P. L. Donaghay, and J. R. V. Zaneveld (1999), Microscale quantification of the absorption by dissolved and particulate material in coastal waters with an ac-9, J. Atmos. Oceanic Technol., 16, 691-707.
Ulloa, O., S. Sathyendranath, and T. Platt (1994), Effect of the particle-size distribution on the backscattering ratio in seawater, Appl. Opt., 33, 70707077.

van de Hulst, H. C. (1981), Light Scattering by Small Particles, 470 pp., Dover, Mineola, N.Y

Voss, K. J., and R. W. Austin (1993), Beam-attenuation measurements error due to small-angle scattering acceptance, J. Atmos. Oceanic Technol., 10, $113-121$.

Zaneveld, J. R. V., D. R. Roach, and H. Pak (1974), The determination of the index of refraction distribution of oceanic particulates, J. Geophys. Res., 79, 4091-4095.

Zaneveld, J. R. V., J. C. Kitchen, and C. M. Moore (1994), The scattering error correction of reflecting-tube absorption meters, Proc. SPIE Int. Soc. Opt. Eng., 2258, 44-55.

Zaneveld, J. R. V., S. Pegau, and J. L. Mueller (2003), Volume scattering function and backscattering coeffiecients: Instruments, characterization, field measurements and data analysis protocols, in Ocean Optics Protocols for Satellite Ocean Color Sensor Validation, Revision 4, vol. IV, Inherent Optical Properties: Instruments, Characterizations, Field Measurements and Data Analysis Protocols, edited by J. L. Mueller et al., NASA Tech. Memo., NASA/TM-2003-211621/Rev4-Vol. IV, 65-76.

F. Baratange and W. S. Pegau, College of Ocean and Atmospheric Sciences, Oregon State University, 104 Ocean Admin. Bldg., Corvallis, OR 97331, USA.

E. Boss, School of Marine Sciences, University of Maine, 5741 Libby Hall, Orono, ME 04469, USA. (emmanuel.boss@maine.edu)

G. Korotaev, M. Lee, and E. Shybanov, Marine Hydrophysical Institute, 2, Kapitanskaya St., Sevastopol, 99011, Ukraine.

M. Twardowski, Western Environmental Technology Laboratories Inc., PO Box 468, Sauderstown, RI 02874, USA. 